\title{
Visual advantage of enhanced flight vision system during NextGen flight test evaluation
}

Lynda J Kramer*, Stephanie J. Harrison, Randall E. Bailey, Kevin J. Shelton, and Kyle K. E. Ellis

NASA Langley Research Center, MS 152, 24 West Taylor Street, Hampton, VA, USA 23681-0001

\begin{abstract}
Synthetic Vision Systems and Enhanced Flight Vision System (SVS/EFVS) technologies have the potential to provide additional margins of safety for aircrew performance and enable operational improvements for low visibility operations in the terminal area environment. Simulation and flight tests were jointly sponsored by NASA's Aviation Safety Program, Vehicle Systems Safety Technology project and the Federal Aviation Administration (FAA) to evaluate potential safety and operational benefits of SVS/EFVS technologies in low visibility Next Generation Air Transportation System (NextGen) operations. The flight tests were conducted by a team of Honeywell, Gulfstream Aerospace Corporation and NASA personnel with the goal of obtaining pilot-in-the-loop test data for flight validation, verification, and demonstration of selected SVS/EFVS operational and system-level performance capabilities.

Nine test flights were flown in Gulfstream's G450 flight test aircraft outfitted with the SVS/EFVS technologies under low visibility instrument meteorological conditions. Evaluation pilots flew 108 approaches in low visibility weather conditions (600 feet to 3600 feet reported visibility) under different obscurants (mist, fog, drizzle fog, frozen fog) and sky cover (broken, overcast).

Flight test videos were evaluated at three different altitudes (decision altitude, 100 feet radar altitude, and touchdown) to determine the visual advantage afforded to the pilot using the EFVS/Forward-Looking InfraRed (FLIR) imagery compared to natural vision. Results indicate the EFVS provided a visual advantage of two to three times over that of the out-the-window (OTW) view. The EFVS allowed pilots to view the runway environment, specifically runway lights, before they would be able to OTW with natural vision.
\end{abstract}

Keywords: FLIR, enhanced flight vision system, enhanced vision, visual advantage, NextGen

\section{INTRODUCTION}

The U.S. air transportation system is undergoing a transformation to accommodate the movement of large numbers of people and goods in a safe, efficient, and reliable manner. ${ }^{1}$ One of the key capabilities envisioned to achieve this Next Generation Air Transportation System (NextGen) is the concept of equivalent visual operations (EVO). EVO is the capability to achieve the safety of current-day Visual Flight Rules (VFR) operations and maintain the operational tempos of VFR irrespective of the weather and visibility conditions.

One research challenge for EVO is the definition of required equipage on the aircraft and at the airport. With today's equipment and regulations, significant investment is required in on-board equipment for navigation, surveillance, and flight control and on the airport for precision guidance systems and approach lighting systems for "all-weather" landing capability. ${ }^{2}$ The levels of equipment redundancy, capability, maintenance, performance, and crew training dramatically increase as landing visibility minima decrease. Synthetic Vision Systems and Enhanced Flight Vision Systems (SVS/EFVS) offer a means of providing EVO capability with significant economic advantages to the operator yet without significant airport infrastructure investment while potentially increasing efficiency and throughput during low visibility operations.

SVS is a computer-generated image of the external scene topography, generated using aircraft attitude, high-precision navigation, and data of the terrain, obstacles, cultural features, and other required flight information. This computer rendered view of the outside world may be presented on a head-down display or head-up display (HUD). EFVS is an electronic means to provide a display (typically on a HUD) of the forward external scene by use of an imaging sensor, such as a Forward-Looking InfraRed (FLIR) or millimeter wave radar. Both SVS and EFVS are "vision-based" technologies intended to create, supplement, or enhance the natural vision of the pilot.

*lynda.j.kramer@nasa.gov; phone 1757 864-8146; fax 1757 864-7793; nasa.gov 


\subsection{Current EFVS rules/operations}

In 2004, Chapter 14 of the Code of Federal Regulations (CFR) Section $§ 91.175$ was amended such that operators with approved EFVS equipment that are conducting straight-in instrument approach procedures may now operate below the published Decision Altitude (DA), Decision Height (DH), or Minimum Descent Altitude (MDA) when using an approved EFVS shown on the pilot's HUD. The key concept under the revisions to §91.175 is that an EFVS can be used in lieu of the required natural vision from the DA/DH/MDA to 100 feet (ft) height above the touchdown (HAT) zone elevation. At the $100 \mathrm{ft} \mathrm{HAT}$, pilots must have sufficient natural vision as required by the instrument approach procedure and to identify the required landing visual references to continue the approach. In addition, FAA Advisory Circular AC $20-167^{3}$ provides guidance on certification and installation of EFVS, and FAA Advisory Circular AC 90-106 ${ }^{4}$ provides guidance for obtaining operational approval to use EFVS in lieu of natural vision to descend below DA/DH or MDA.

\subsection{Proposed EFVS operations changes}

The FAA started a rulemaking project to expand operational credit for EFVS beyond what is currently authorized by the regulations (under 14 CFR $\S 91.175)$ ) ${ }^{5,6}$ RTCA DO- $315 \mathrm{~A}^{7}$ was drafted to establish performance standards in concert with this rulemaking project. Minimum system performance standards are now published for EFVS operations through the approach to touchdown in visibility as low as $1000 \mathrm{ft}$ runway visual range (RVR) by use of an approved EFVS in lieu of natural vision. Simply stated, (in DO-315 $\mathrm{A}^{7}$ ) the visual segment of the approach can now be accomplished by using either enhanced flight visibility or natural vision. Enhanced flight visibility is defined in the Federal Aviation Regulations (FARs) as "the average forward horizontal distance, from the cockpit of an aircraft in flight, at which prominent topographical objects may be clearly distinguished and identified by day or night by a pilot using an enhanced flight vision system.” Past NASA research ${ }^{8}$ supports the viability of this expanded EFVS visual segment where it was shown that using an EFVS to hand fly approaches to touchdown resulted in excellent localizer tracking performance (less than 1/3 dot localizer deviation between $300 \mathrm{ft}$ and $100 \mathrm{ft}$ HAT) and an improvement in glideslope tracking performance.

On June 11, 2013, the FAA published a Notice of Proposed Rulemaking (NPRM), FAA-2013-0485 Notice Number 1209, to permit operators to use an EFVS in lieu of natural vision to continue descending from $100 \mathrm{ft}$ HAT through touchdown and rollout on certain straight-in instrument approaches in visibilities as low as 1000 RVR. ${ }^{9}$ The rule would also permit certain EFVS operators to dispatch, release, or takeoff under instrument flight rules and initiate and continue an approach, when the destination airport weather is below authorized visibility minimums for the runway of intended landing. The NPRM includes pilot training, flight experience, and proficiency requirements for operators who use EFVS in lieu of natural vision to descend below DA, DH or MDA and revisions for the pilot compartment view certification requirements for all vision systems.

\subsection{SVS/EFVS flight test}

Simulation ${ }^{10}$ and flight test ${ }^{11}$ experiments were conducted as part of a formal collaboration between NASA Langley Research Center (LaRC) and the FAA under an Interagency Agreement (IA) to support the introduction and use of SVS/EFVS advanced cockpit vision technologies in NextGen operations. This work builds from and extends the current operational use and certification of existing SVS/EFVS technologies toward all-weather, low visibility operations for NextGen.

Of particular note, an SVS/EFVS flight test ${ }^{11}$ was conducted, in partnership with Honeywell and Gulfstream, to evaluate:

1. Operational feasibility, pilot workload, and pilot acceptability of conducting a straight-in instrument approach with published vertical guidance using EFVS during approach, landing, roll-out, and runway exit in visibility of $1000 \mathrm{ft}$ RVR.

2. Operational feasibility, pilot workload, and pilot acceptability of conducting an instrument landing system approach to a $150 \mathrm{ft}$ Decision Height (DH) using SVS followed by a transition to natural out-the-window (OTW) visual cues for landing with the visibility as low as $1400 \mathrm{ft}$ RVR.

The focus of this paper is to attempt to quantify the visual advantage (or increase in forward visual range) afforded to a pilot using an imaging sensor (EFVS/FLIR) compared to natural vision while making approaches in low visibility operating conditions with varying weather obscurants and sky cover. As such, only the EFVS flight trials were considered. 
Flight test video from nine flights flown in Gulfstream's G450 flight test aircraft outfitted with Kollsman EFVS II technology under low visibility instrument meteorological conditions were used to determine the visual advantage benefits. During this flight test, evaluation pilots flew 108 approaches in low visibility weather conditions (600 ft to $3600 \mathrm{ft}$ reported visibility) under different obscurants (mist, fog, drizzle fog, frozen fog) and sky cover (broken, overcast). Flight test video were evaluated at three different altitudes (decision altitude, $100 \mathrm{ft}$ radar altitude, and touchdown) to assess if a 'visual advantage' can be quantified using the EFVS/FLIR imagery compared to natural vision. Details of the test set-up and operation are contained in Reference 11.

\section{METHODOLOGY}

\subsection{Test aircraft}

The flight test was conducted using Gulfstream's G450 flight test aircraft N401SR, S/N 4001 (Figure 1). The test aircraft was equipped with certified avionics and software, including the Honeywell Synthetic Vision-Primary Flight Display (SV-PFD) and monochromatic EFVS Head-Up Display (HUD) with display of conformal symbolic information, flight information, and FLIR imagery (Figure 2). The HUD is the Rockwell-Collins' model HGS 6250, and the FLIR is the Kollsman Enhanced Vision System (EVS) II infra-red camera.

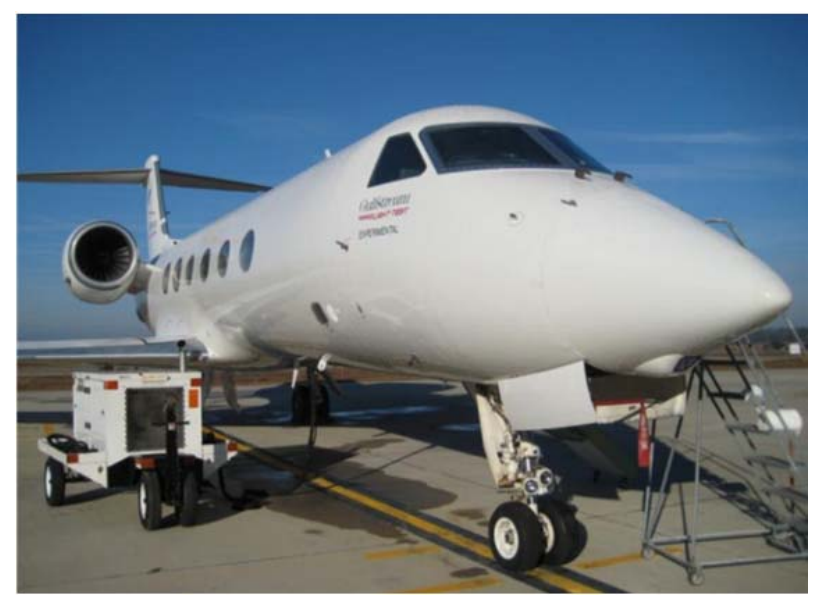

Figure 1. Gulfstream G450 test aircraft.

The G450 is one of the Gulfstream test aircraft used for on-going test and certification activities and is equipped to record data and video. The G450 test aircraft's avionics were not experimental equipment but were the current standard avionics suite as certified and in service. The G450 aircraft was also certified with an EFVS system which allows "operational approval" for approaches with descent below published minima down to $100 \mathrm{ft}$ HAT as documented in Code of Federal Regulations (CFR) 14 Part 91.175(l) and discussed in Advisory Circular AC 90-106. ${ }^{4}$ 

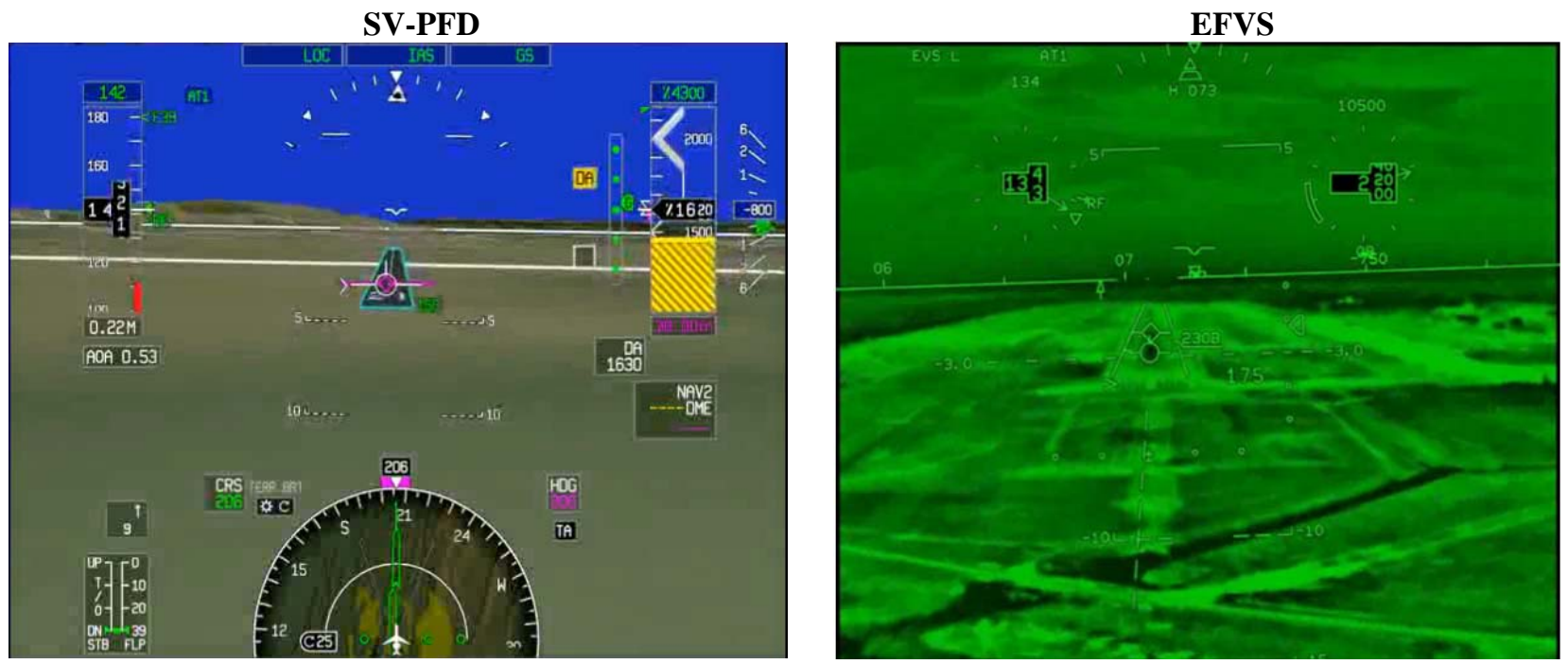

Figure 2. SV-PFD (left picture) and EFVS imagery and symbology on HUD (right picture).

Over 300 parameters were recorded at 50 samples per second during each approach and landing run. Several relevant parameters, including path error (localizer, glideslope, vertical speed) and touchdown performance (sink rate and speed at touchdown, distance from the threshold, and distance left or right of centerline), were measured for analysis. Nine channels of video were recorded on three separate digital video recorders (DVR). The three DVR recordings were comprised of a quad arrangement of cameras (Figure 3, left picture), a quad arrangement of head-down instruments (Figure 3, right picture), and) and a single channel of EFVS Imagery (FLIR) and Symbology (Figure 2, right picture).
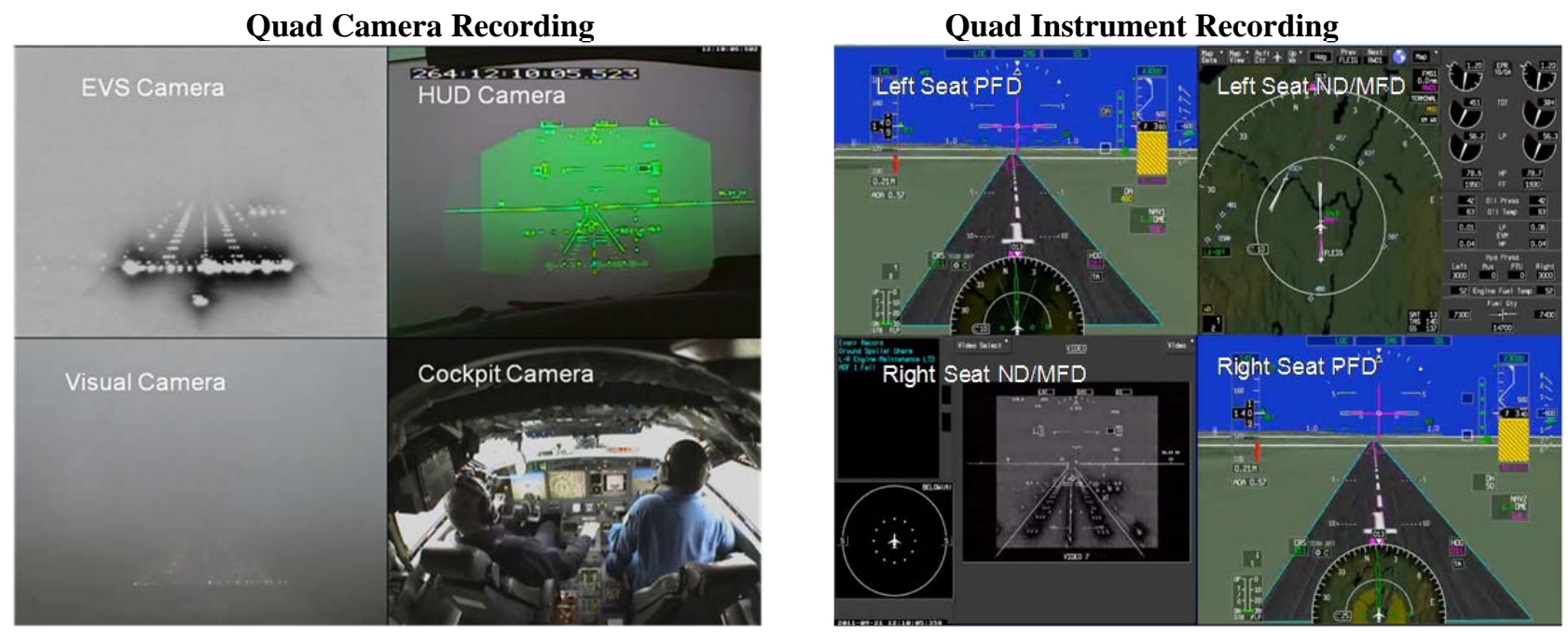

Figure 3. Quad camera recording (left picture) and quad instrument recording (right picture).

The nine video sources included:

- $\quad$ EVS Camera (Raw FLIR imagery)

- HUD Camera

- Visual Out the Window Camera

- Cockpit Area Camera

- Left Seat Primary Flight Display
- Left Seat Navigation/Multi-Purpose Display

- Right Seat Navigation/Multi-Purpose Display

- $\quad$ Right Seat Primary Flight Display

- Combined HUD \& EFVS Imagery presented on the HUD 


\subsection{Evaluation pilots}

Six Evaluation Pilots (EPs) participated in the flight evaluations and represented a diverse mix of experience.

The EPs met the following experience criteria:

- $\quad$ Each pilot held an Airline Transport Pilot rating

- Each pilot had significant HUD experience, having flown at least 100 hrs of HUD, pilot-in-command operations.

- Each pilot was type-rated in a Gulfstream G-IV, G-V, and G450, G550, or G650 aircraft and had EFVS qualifications and EFVS operational experience. Total time in the Gulfstream aircraft was greater than 200 hrs.

The average experience of the EPs was 9100 hours of flight time with an average of 28 years of flying. Most of the EPs flew on multiple evaluation flights.

\subsection{Procedures}

All EFVS testing was flown with the EP occupying the left seat using the HUD, a Gulfstream Safety Pilot (SP) occupying the right seat, and an additional Safety Observer (SO) occupying the center jump seat. EFVS test operations were conducted under an FAA waiver to the current Title 14 of the CFR $\S 91.175$ allowing these test flights (i.e., in an operation that is not currently approved). This waiver allowed the use of EFVS or natural vision to see the required visual references, as to continue descent below the DA/DH through landing. Safety procedures required that the SP have positive visual acquisition of the required landing references by $50 \mathrm{ft}$ above touchdown elevation.

The EPs flew straight-in instrument approaches adhering to published approach procedures (other than the waivered minimums) to the runway. All approaches were flown with the EP manually flying the aircraft below $1000 \mathrm{ft}$ above ground level to a landing. The initial approach procedure was often flown with the auto-pilot engaged, following the approach procedure. Auto-throttles were used for all approaches. Detailed call-out procedures for both the EP and SP were utilized for all approaches ensuring safety throughout the approach and providing clear evidence of the acquisition of the required approach and landing visual references as per §91.175.

\subsection{Test operations}

All test flights originated at the Savannah/Hilton Head International Airport (KSAV) which is the location of the Gulfstream manufacturing and flight test facilities. Table 1 lists all of the airports and runways utilized in the flight test operations.

The test locations were determined in near real-time using weather operations support and from Automated Surface Observing System (ASOS) and Automated Terminal Information Services (ATIS) reports while in route to the target area to locate low visibility conditions. The actual operating conditions obviously changed from these targets until the aircraft arrived on station, and they varied as approach and landing operations were conducted.

\subsection{Test conditions - weather}

For EFVS operations the target visibility was $1000 \mathrm{ft}$ RVR to $1 / 4$ statute mile (SM) with a ceiling of 100 feet. The exact desired weather conditions for the test were achieved on several occasions. Over the course of multiple approaches, the visibility and ceiling naturally varied at each airport, giving a nice range of data on either side of the target conditions. A sampling of weather conditions for data collection at the different airports is shown in Table 1. 
Table 1. Test airports and conditions.

\begin{tabular}{|c|c|c|c|c|c|}
\hline Airport & Approach & $\begin{array}{c}\text { Reported } \\
\text { Visibility } \\
\text { (SM) }\end{array}$ & $\begin{array}{c}\text { Reported } \\
\text { RVR } \\
\text { (ft) }\end{array}$ & $\begin{array}{c}\text { Reported } \\
\text { Ceiling } \\
\text { (ft) }\end{array}$ & Weather Notes \\
\hline $\begin{array}{l}\text { Shenandoah Valley } \\
\text { Regional }\end{array}$ & KSHD ILS 05 & $1 / 4-1 / 2$ & & 100 & $\begin{array}{l}\text { Fog, Overcast, Thin but dense } \\
\text { layer }\end{array}$ \\
\hline Altoona Blair County & KAOO ILS 21 & $1 / 2$ & & 100 & Fog, Overcast \\
\hline Portsmouth Intl./Pease & KPSM ILS 34 & $1 / 8$ & $900-1200$ & 100 & Fog, Broken \\
\hline $\begin{array}{l}\text { Bar Harbor -Hancock } \\
\text { County }\end{array}$ & KBHB ILS 22 & $1 / 4$ & & 200 & Fog, Overcast \\
\hline $\begin{array}{l}\text { Greater Binghamton/ } \\
\text { Edwin A. Link Field }\end{array}$ & KBGM ILS 16 & $<1 / 4$ & 600 & 100 & Fog, Indefinite ceiling \\
\hline Albany International & KALB ILS 01 & $1 / 4$ & & 200 & Mist \\
\hline Vidalia Regional & KVDI ILS 24 & $1 / 4$ & & 100 & Fog, Overcast \\
\hline $\begin{array}{l}\text { Savannah/Hilton Head } \\
\text { International }\end{array}$ & KSAV ILS 10 & $11 / 4$ & & 200 & Scattered thin \\
\hline Acadiana Regional & KARA ILS 34 & $1 / 4$ & & 100 & $\begin{array}{l}\text { Broken, Overcast } \\
\text { Dense thin layer at } 100-50 \mathrm{ft}\end{array}$ \\
\hline Esler Regional & KESF ILS 27 & $1 / 4$ & & 100 & Fog, Overcast \\
\hline $\begin{array}{l}\text { Alexandria } \\
\text { International }\end{array}$ & KAEX ILS 14 & $1 / 4$ & & 100 & Fog, Overcast \\
\hline $\begin{array}{l}\text { Cincinnati Muni } \\
\text { Airport-Lunken Field }\end{array}$ & KLUK ILS 21 & $1 / 4$ & 2400 & 100 & Fog \\
\hline $\begin{array}{l}\text { Akron-Canton } \\
\text { Regional }\end{array}$ & KCAK ILS 19 & $1 / 4$ & & 100 & Freezing Fog \\
\hline $\begin{array}{l}\text { Youngstown/Warren } \\
\text { Regional }\end{array}$ & KYNG ILS 32 & $1 / 8$ & 1000 & 200 & Freezing Fog \\
\hline
\end{tabular}

\subsection{Flights summary}

There were seven data collection flights conducted from July 20 to Oct 28, 2011. All flight time totaled approximately 38 hours with the seven data collection flights comprising approximately 35 flight hours. Data were collected at 15 different airports and utilized 16 different runways.

There were 107 approaches flown, 80 were EFVS approaches (75\%) and 27 were SVS approaches (25\%). Only the EFVS approaches are applicable to the evaluation of visual advantage which is the focus of this paper. Out of the 80 EFVS approaches, seven were culled out of the data analysis for various extraneous reasons such as: Approach Lightning System (ALS) automatically turning off, or EP mistakenly left autopilot on during much of the approach, etc. These events were anomalous and caused significant deviations from our nominal operation and therefore, were not representative of the other approaches.

Of the 73 useable EFVS approach evaluations, 53 (73\%) resulted in a touchdown and 20 (27\%) resulted in missed approach. Eight of the EFVS approaches were to an offset runway (KBGM). The 20 missed EFVS approaches were all conducted safely with the go-around decision correctly determined based on conditions. Both touchdown and missed approach runs were analyzed in this paper. 


\subsection{Determination of forward horizontal visible distance from cockpit}

Snapshots of flight test video were taken from the quad camera DVR recordings (Figure 3, left picture) and EFVS DVR recordings (Figure 2, right picture) at the Decision Altitude (DA), 100 feet radar altitude (RA) call out, and as the plane touched down. The $100 \mathrm{ft}$ RA audio callout was used as an approximation of $100 \mathrm{ft}$ HAT due to difficulties in determining $100 \mathrm{ft}$ HAT using the available video playback data. The $100 \mathrm{ft}$ RA audio callout was available on each DVR recording so consistent snapshots could be made among the recordings. The quad camera recording was comprised of the EVS (FLIR) camera, visual (OTW) camera, HUD camera, and a cockpit camera. The snapshots from the quad camera DVR recordings were used to count the lights that approximated what the pilot could see using the FLIR camera and OTW and thus, attempt to quantify the EFVS visual advantage. The snapshots from the EFVS DVR recordings were used to estimate the distance to the first visible light at DA and $100 \mathrm{ft} \mathrm{RA}$.

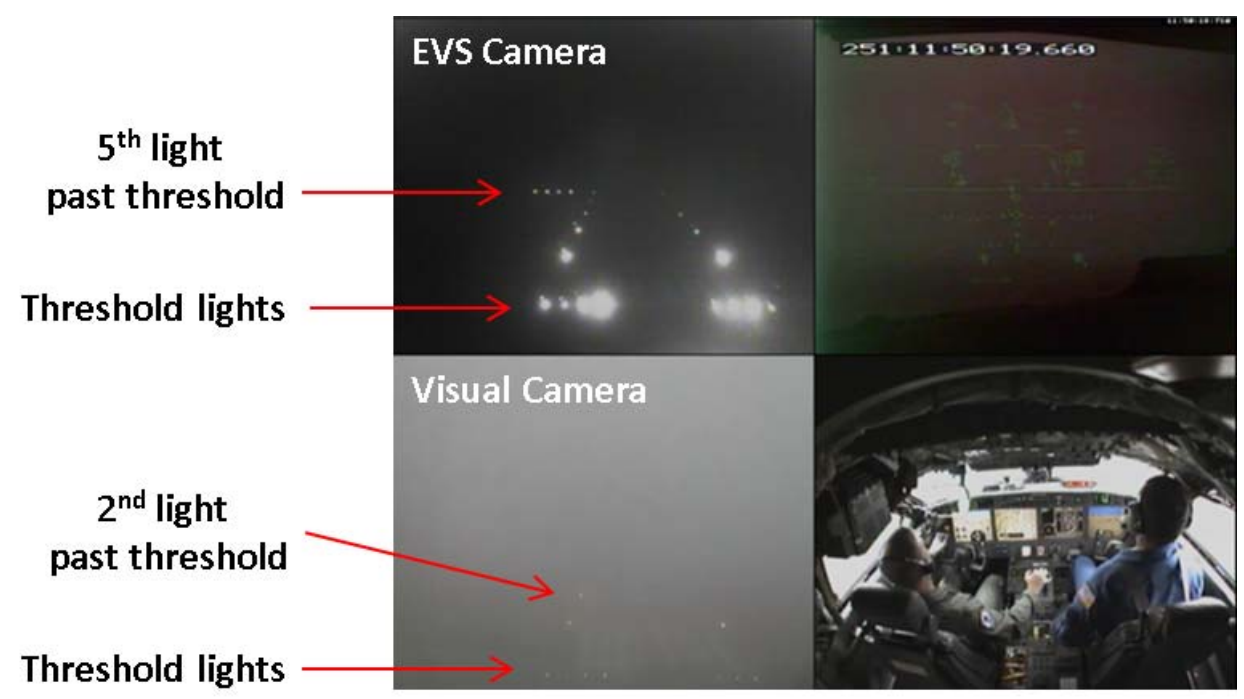

Figure 4. Quad camera recording.

Visual advantage was estimated by counting the runway edge lights that were visible in the respective video images, starting with the threshold lights. The threshold lights were counted as one light if they were visible. Each runway edge light was counted as one light if visible. For example, in the quad camera image seen in Figure 4, in the EVS view (upper left camera), the threshold lights are visible in addition to 5 runway edge lights on the left side of the runway. This would count as 6 lights visible through the EVS. Two runway edge line lights plus the threshold lights are visible out the window on the left side of the runway (Figure 4, bottom left camera). This would count as three lights visible OTW, compared to the six seen through the EVS. The runway edge lights are 200 feet apart. The touchdown lights and visual approach slope indicator (VASI) lights were used if needed to order to estimate runway edge lights that were further down the runway. The VASI lights are normally 1000 feet beyond the runway threshold. The touchdown zone lights, if equipped, extend 3,000 feet down the runway and are placed at 100 foot increments.

In most cases, at the DA, the MALSR (Medium-intensity Approach Lighting System with Runway Alignment Indicator Lights) approach lighting system produced the only visible lights. MALSRs consist of nine light bars and five flashing lights spaced every 200 feet as you approach the runway. These lights, in addition to any visible runway edge lights, were counted and recorded.

The altitude readout in the HUD camera image (Figure 3, left picture upper right quadrant) was used to determine when the aircraft was crossing the DA, and the radar altimeter was used to determine when the aircraft had touched down. The HUD camera was not synchronized with the HUD projector, and this occasionally caused the HUD camera image to fade in and out. (The HUD projector image which was presented to the EP during EFVS runs was steady and did not fade in and out.) Snapshots were not taken for runs where the HUD camera image was unavailable at the DA or touchdown. As a result, there were not an equivalent number of snapshots taken at the DA, $100 \mathrm{ft}$ RA, and touchdown points due to this synchronization issue. 
The number of visible lights was used to calculate the forward horizontal distance from the cockpit that was visible to the pilot through the EFVS and OTW. Since all counted lights were recorded as being 200 feet apart, the number of lights was multiplied by 200 and recorded as being the forward horizontal visible distance. This procedure assumed that the aircraft was 200 feet from the first light.

Since this assumption isn't always the case, the distance to the first light was estimated. The look-down angle from the horizon line to the first visible light (referred to as $\xi$ in the figure below) was estimated using the pitch ladder from the snapshots taken from the EFVS DVR recordings (Figure 2, right picture). This measurement was done at the DA and at 100 feet RA. Overall, this provided a better estimate of how far down the runway the pilot could see.

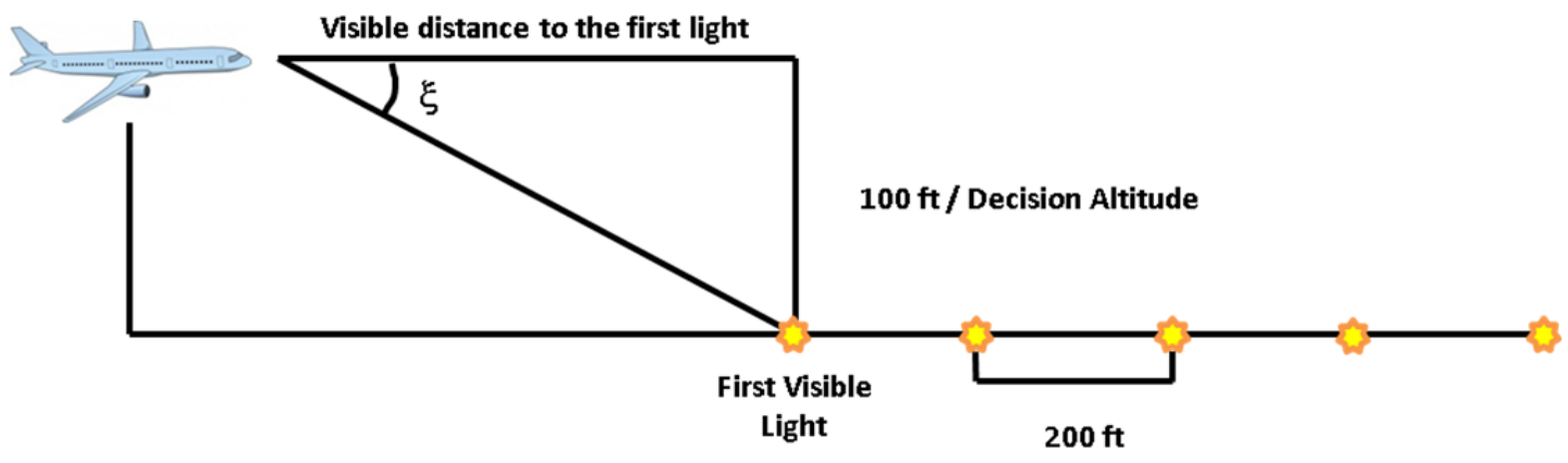

Figure 5. Visible distance to first visible light.

\subsection{Determination of reported visibility, obstruction, and sky cover}

If the reported RVR was available, then RVR was used as reported visibility for this analysis. If reported visibility in statute miles was the only visibility available then it was converted from miles to feet and recorded for reported visibility. It should be remembered that reported visibility does not necessarily represent the actual visibility that the pilot might experience coming into an approach.

Meteorological Terminal Aviation Routine Weather Report (METAR) data was also recorded for each approach performed during the flight test. A METAR historical record (http://www.ogimet.com/metars.phtml.en) and METAR translator (http://www.iflightplanner.com/Resources/MetarTafTranslator.aspx) were used to record this data. The reported obstruction and sky cover were provided in the METAR data. Obstructions that were reported during the EFVS flight test runs included fog, mist, drizzle fog, and frozen fog. Reported sky cover included overcast and broken sky cover.

\section{RESULTS}

Visual advantage is defined as an increase in average forward horizontal distance from the cockpit of an aircraft provided by an imaging sensor, such as FLIR, over that provided by natural vision.

Two metrics, the visual advantage difference and the visual advantage factor, were used to quantify any increase in forward horizontal visible distance by EFVS over natural vision. The visual advantage difference was calculated by subtracting the mean EFVS visual distance by the mean OTW visible distance. A positive value of this metric indicates visual advantage by the EFVS (FLIR sensor) over natural vision. The visual advantage factor was calculated by dividing the mean distance visible through the EFVS by the mean distance visible OTW. Note that if there were no lights visible OTW, then the visual advantage factor could not be calculated.

The forward horizontal visible distance was quantified by calculating the horizontal visual distance from the pilot's eye to the first light, using the look down angle, and adding to this the number of counted visible runway edge lights, excluding the first visible light, and multiplying by 200, the distance between runway edge lights. The weighted average of the visual distance was calculated at the decision altitude, $100 \mathrm{ft}$ radar altitude, and touchdown. The weighted average takes into consideration the number of approaches used to calculate the visual distance. 


\subsection{Visual advantage by reported visibility at $100 \mathrm{ft}$ radar altitude}

Table 2 provides the visual advantage difference, the visual advantage factor (if calculable) and the number of approaches flown at each reported visibility level at three distinct points on the approach (DA, $100 \mathrm{ft}$ RA, and touchdown). Also provided in this table are the weighted averages for the two visual advantage metrics at the 3 distinct approach points.

Table 2. Visual advantage under reported visibilities at distinct points of approach.

\begin{tabular}{|c|c|c|c|c|c|c|}
\hline $\begin{array}{l}\text { Approach } \\
\text { Point }\end{array}$ & $\begin{array}{c}\text { Reported } \\
\text { Visibility (ft) }\end{array}$ & $\begin{array}{c}\text { EFVS } \\
\text { Distance (ft) }\end{array}$ & $\begin{array}{c}\text { OTW } \\
\text { distance } \\
\text { (ft) }\end{array}$ & $\begin{array}{c}\text { Visual } \\
\text { Advantage } \\
\text { Difference (ft) }\end{array}$ & $\begin{array}{c}\text { Visual } \\
\text { Advantage } \\
\text { Factor }\end{array}$ & $\begin{array}{l}\text { Number of } \\
\text { Approaches }\end{array}$ \\
\hline \multirow{9}{*}{ DA } & 600 & 2525 & 1641 & 884 & 1.5 & 4 \\
\hline & 900 & 2087 & 0 & 2087 & - & 3 \\
\hline & 1000 & - & - & - & - & - \\
\hline & 1200 & 2295 & 961 & 1334 & 2.4 & 24 \\
\hline & 1800 & 2109 & 0 & 2109 & - & 1 \\
\hline & 2400 & 1992 & 0 & 1992 & - & 2 \\
\hline & 3000 & - & - & - & - & - \\
\hline & 3600 & 2752 & 1552 & 1200 & 1.8 & 1 \\
\hline & Weighted Average & 2294 & 891 & 1403 & 1.9 & \\
\hline \multirow{9}{*}{$100 \mathrm{ft}$ RA } & 600 & 619 & 154 & 465 & 4.0 & 7 \\
\hline & 900 & 1744 & 901 & 843 & 1.9 & 7 \\
\hline & 1000 & 484 & 0 & 484 & - & 1 \\
\hline & 1200 & 1530 & 654 & 876 & 2.3 & 37 \\
\hline & 1800 & 1886 & 0 & 1886 & - & 1 \\
\hline & 2400 & 1694 & 379 & 1315 & 4.5 & 4 \\
\hline & 3000 & 1098 & 1198 & -100 & 0.9 & 1 \\
\hline & 3600 & 1055 & 322 & 733 & 3.3 & 2 \\
\hline & Weighted Average & 1425 & 582 & 843 & 2.6 & \\
\hline \multirow{9}{*}{ TD } & 600 & 733 & 33 & 700 & 22.0 & 3 \\
\hline & 900 & 1357 & 871 & 486 & 1.6 & 7 \\
\hline & 1000 & 700 & 0 & 700 & - & 1 \\
\hline & 1200 & 1335 & 717 & 618 & 1.9 & 33 \\
\hline & 1800 & 1100 & 200 & 900 & 5.5 & 1 \\
\hline & 2400 & 1300 & 350 & 950 & 3.7 & 4 \\
\hline & 3000 & 1500 & 1400 & 100 & 1.1 & 1 \\
\hline & 3600 & 1100 & 450 & 650 & 2.4 & 2 \\
\hline & Weighted Average & 1278 & 649 & 629 & 3.2 & \\
\hline
\end{tabular}

The average forward horizontal visible distance provided by the EFVS was greater than that provided by natural vision at the three distinct approach points for all reported visibility levels, except for the $3000 \mathrm{ft}$ visibility level at the $100 \mathrm{ft}$ RA approach point (Table 2 and Figure 6). For that one approach, the pilot could see approximately 1098 feet through the EFVS and 1198 feet OTW. These visual distance values are considered to be essentially equivalent. 
With weighted average visual advantage factor values of 1.9 to 3.2 (Table 2), during these approaches the EFVS provided forward horizontal visible distance increases of two to three times that of the OTW natural vision view. The EFVS allowed pilots to view the runway environment, specifically runway lights, before they would be able to out the window.

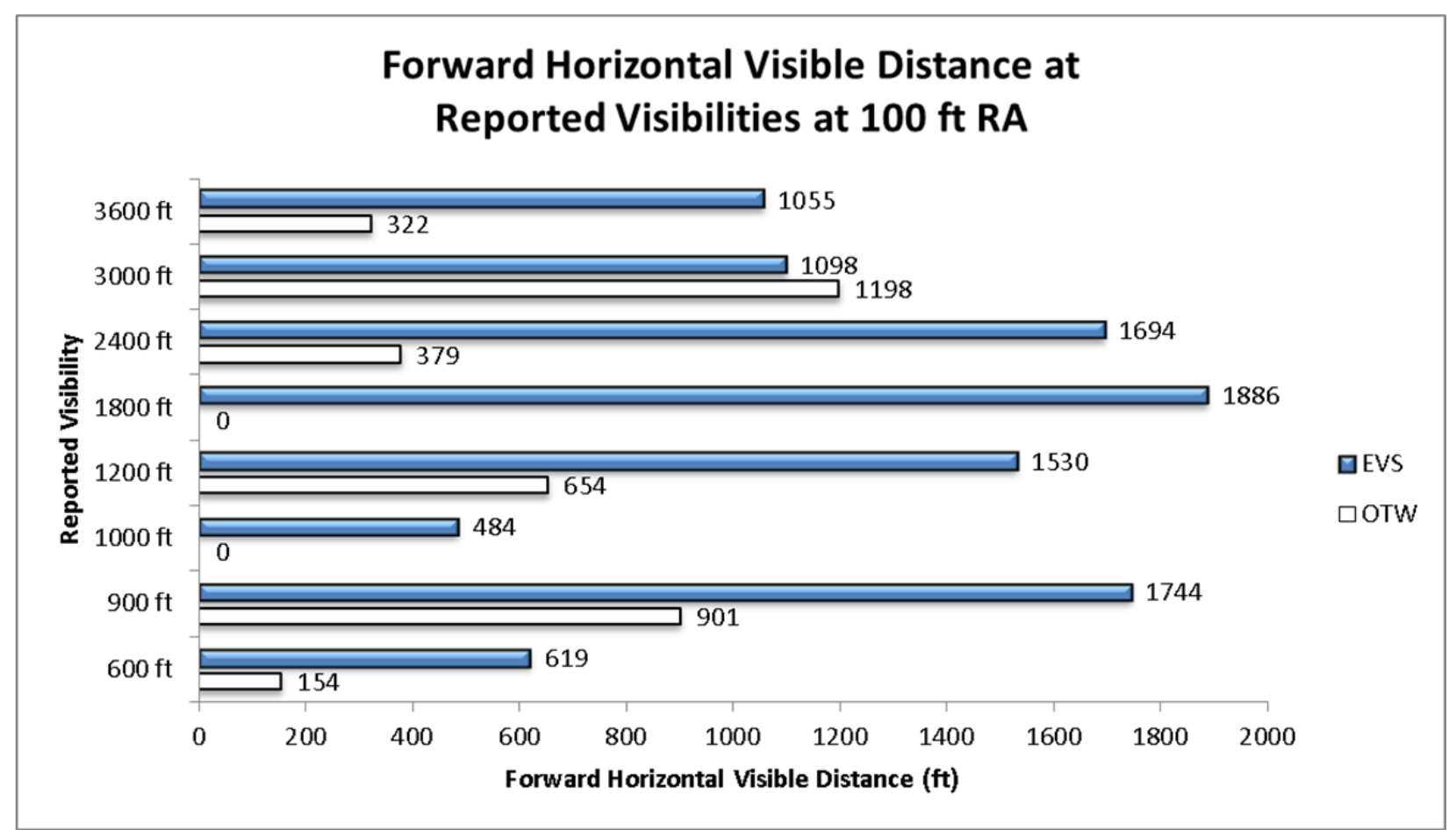

Figure 6. Forward horizontal visible distance at reported visibilities at $100 \mathrm{ft}$ RA.

Examination of boxplots at the DA, $100 \mathrm{ft} \mathrm{RA}$, and touchdown (Figures 7-9, respectively) show that the data is skewed for the OTW forward horizontal visible distance. On each box, the central mark is the median, the edges of the box are the 25th and 75th percentiles, the whiskers extend to the most extreme data points not considered outliers, and outliers are plotted individually. The pilots did not see any lights with natural vision (i.e., zero ft visible distance OTW) for $57 \%$ of the approaches at DA, $40 \%$ of the approaches at $100 \mathrm{ft} \mathrm{RA}$, and $21 \%$ of the landings, which resulted in lowering the mean OTW visible distance values (Table 2) at the applicable reported visibility levels. Table 3 shows the mean forward horizontal visible distances for the EFVS and natural vision and the visual advantage factor at the three approach points when using only the OTW approaches with non-zero values. The EFVS still provided increases in forward horizontal visible distance 1.2 to 1.7 times greater than that provided by natural vision when considering only the non-zero OTW visible distance values.

Even though the reported visibility was between 600 and $3600 \mathrm{ft}$ for the approaches flown, the estimated OTW forward visible distance varied greatly at the three approach points where it ranged from a minimum of zero $\mathrm{ft}$ to maximum values of $5510 \mathrm{ft}$ at DA, 3014 at $100 \mathrm{ft} \mathrm{RA}$, and $1650 \mathrm{ft}$ at touchdown (Figures 7-9). The EFVS forward visible distance ranged from 1060-5710 ft at DA, 221-3610 ft at $100 \mathrm{ft}$ RA, and 600-1750 at touchdown.

Table 3. Visual advantage factor when considering only approaches with non-zero OTW visible distance values.

\begin{tabular}{|c|c|c|c|c|}
\hline Approach Point & EFVS Distance (ft) & OTW Distance (ft) & Visual Advantage Factor & Number of Approaches \\
\hline DA & 2545 & 2078 & 1.2 & 15 \\
\hline $100 \mathrm{ft}$ RA & 1734 & 970 & 1.8 & 36 \\
\hline TD & 1377 & 823 & 1.7 & 41 \\
\hline
\end{tabular}




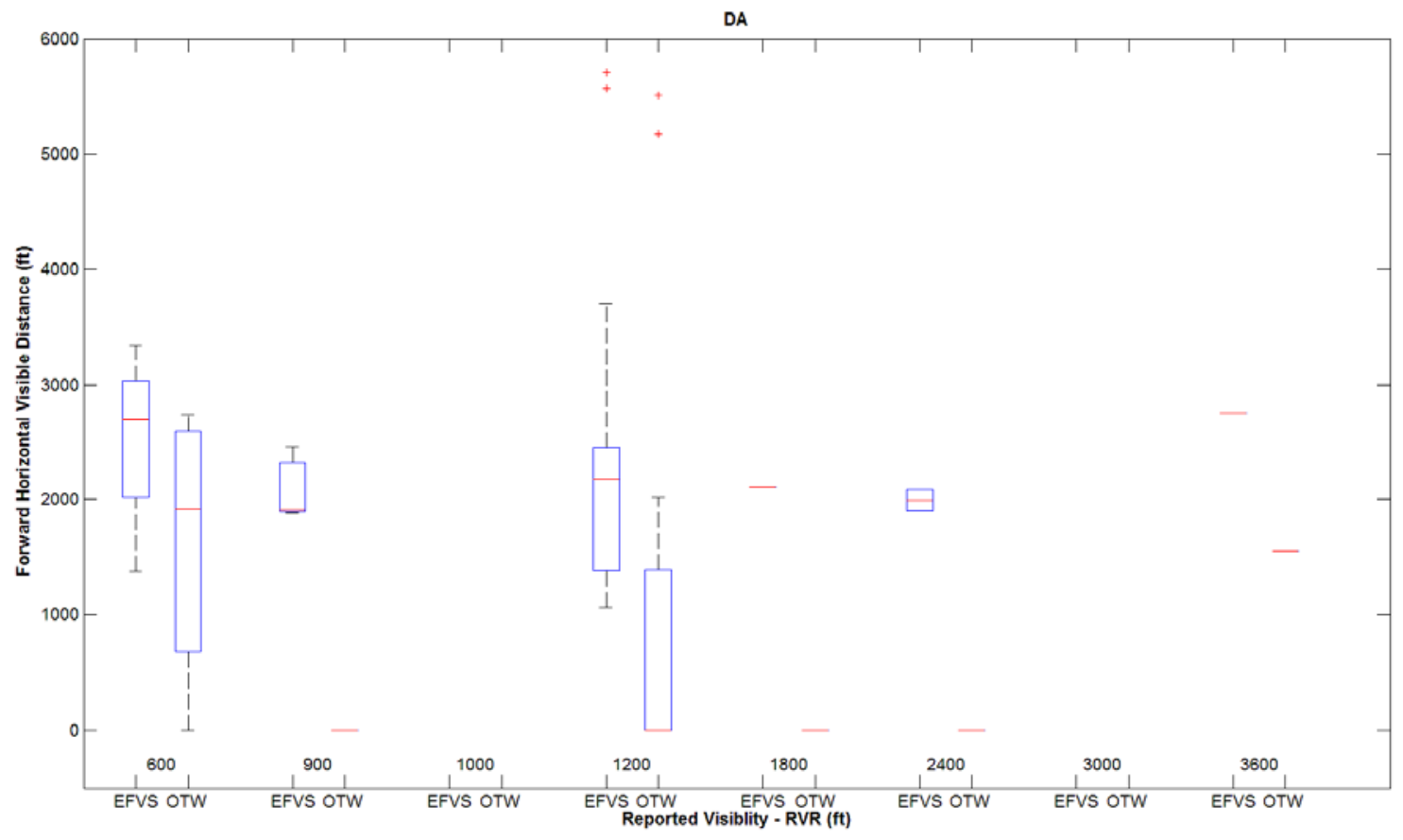

Figure 7. Box plot of forward horizontal visible distance at reported visibilities at Decision Altitude (DA).



Figure 8. Box plot of forward horizontal visible distance at reported visibilities at $100 \mathrm{ft}$ RA. 




Figure 9. Box plot of forward horizontal visible distance at reported visibilities at touchdown.

\subsection{Visual advantage by obscurant and approach point}

Table 4 provides the visual advantage metrics and number of approaches flown within each obscurant type at three distinct points on the approach (DA, $100 \mathrm{ft}$ RA, and touchdown). Table 4 also provides the weighted averages for the two visual advantage metrics at the three distinct approach points.

Table 4. Visual advantage under different obscurants at distinct points of approach.

\begin{tabular}{|c|c|c|c|c|c|c|}
\hline $\begin{array}{c}\text { Approach } \\
\text { Point }\end{array}$ & Obscurant & $\begin{array}{c}\text { EFVS } \\
\text { Distance } \\
\text { (ft) }\end{array}$ & $\begin{array}{c}\text { OTW } \\
\text { Distance } \\
\text { (ft) }\end{array}$ & $\begin{array}{c}\text { Visual } \\
\text { Advantage } \\
\text { Difference (ft) }\end{array}$ & $\begin{array}{c}\text { Visual } \\
\text { Advantage } \\
\text { Factor }\end{array}$ & $\begin{array}{c}\text { Number of } \\
\text { Approaches }\end{array}$ \\
\hline \multirow{4}{*}{ DA } & Frozen Fog & 3096 & 0 & 3096 & - & 2 \\
\cline { 2 - 7 } & Drizzle Fog & 2494 & 779 & 1715 & 3.2 & 6 \\
\cline { 2 - 7 } & Fog & 2174 & 1134 & 1039 & 1.9 & 22 \\
\cline { 2 - 7 } & Mist & 2263 & 310 & 1953 & 7.3 & 5 \\
\cline { 2 - 7 } & Weighted Average & 2294.0 & 890.7 & 1403.3 & 2.8 & \\
\hline \hline \multirow{4}{*}{ fon ft RA } & Frozen Fog & 1701 & 754 & 947 & 2.3 & 4 \\
\cline { 2 - 7 } & Drizzle Fog & 2327 & 744 & 1583 & 3.1 & 6 \\
\cline { 2 - 7 } & Fog & 1202 & 549 & 653 & 2.2 & 39 \\
\cline { 2 - 7 } & Mist & 1623 & 549 & 1074 & 3.0 & 11 \\
\cline { 2 - 7 } & Weighted Average & 1424.9 & 582.2 & 842.7 & 2.4 & \\
\cline { 2 - 7 } & Frozen Fog & 1150 & 600 & 550 & 1.9 & 4 \\
\cline { 2 - 7 } & Drizzle Fog & 1550 & 1080 & 470 & 1.4 & 5 \\
\cline { 2 - 7 } & Fog & 1247 & 605 & 642 & 2.1 & 32 \\
\cline { 2 - 7 } & Mist & 1291 & 600 & 691 & 2.2 & 11 \\
\cline { 2 - 7 } & Weighted Average & 1277.9 & 649.0 & 628.8 & 2.0 & 1277.9 \\
\hline \hline
\end{tabular}


Under all reported obscurants, including mist, fog, drizzle fog, and frozen fog, the forward horizontal visible distance provided by the EFVS was greater than that provided by natural vision at the decision altitude, 100 feet RA, and touchdown of each flight. When flying in frozen fog, the pilot did not see any runway lights using natural vision at the decision altitude, but the pilot was able to see an average of 3096 feet forward horizontal distance from the cockpit using EFVS (Figure 10). This distance is a significant improvement in visual range. Across the combinations of approach point and obscurant (Table 4), the visual advantage difference metric ranged from 470 to $3096 \mathrm{ft}$ and the visual advantage factor metric indicated that the EFVS provided increases in forward horizontal visible distance 1.4 to 7.3 times greater than that provided by natural vision. With weighted average visual advantage factor values of 2.0 to 2.8 (Table 4), the EFVS provided forward horizontal visible distance increases of two to three times that of the OTW natural vision view when flying through various types of fog and mist. The EFVS allowed pilots to view the runway environment, specifically runway lights, before they would be able to out the window. This increases a pilot's situational awareness and provides for safer landings.



Figure 10. Forward horizontal visible distance under different obscurants at distinct approach points.

As noted in Section 3.1, the mean OTW forward horizontal visible distances (Table 4) are skewed due to approaches where the value for this measure was zero $\mathrm{ft}$ (i.e., no lights visible OTW). For the obscurant mist, $80 \%$ of the DA approaches and 37\% of the $100 \mathrm{ft}$ RA approaches had no lights visible OTW in the snapshots taken at these approach points, but the mean EFVS visible distances for these approaches were $2141 \mathrm{ft}$ at DA and $1378 \mathrm{ft}$ at $100 \mathrm{ft}$ RA. Similarly, for the obscurant fog, $50 \%$ of the DA approaches, $46 \%$ of the $100 \mathrm{ft} \mathrm{RA}$, and $31 \%$ of the landings had no lights visible OTW in the snapshots taken at these approach points, but the mean EFVS visible distances for these 
approaches were $1271 \mathrm{ft}$ at DA, $926 \mathrm{ft}$ at $100 \mathrm{ft} \mathrm{RA}$, and $920 \mathrm{ft}$ at landing. The EFVS effectively increased the pilot's forward horizontal visible distance by $1000 \mathrm{ft}$.

\subsection{Visual advantage by sky cover and approach point}

Table 5 provides the visual advantage metrics and number of approaches flown within each sky cover type at three distinct points on the approach (DA, $100 \mathrm{ft} \mathrm{RA}$, and touchdown). Table 5 also provides the weighted averages for the two visual advantage metrics at the three distinct approach points.

Table 5. Visual advantage under different sky cover at distinct points of approach.

\begin{tabular}{|c|c|c|c|c|c|c|}
\hline $\begin{array}{c}\text { Approach } \\
\text { Point }\end{array}$ & Sky Cover & $\begin{array}{c}\text { EFVS } \\
\text { Distance } \\
\text { (ft) }\end{array}$ & $\begin{array}{c}\text { OTW } \\
\text { Distance } \\
\text { (ft) }\end{array}$ & $\begin{array}{c}\text { Visual } \\
\text { Advantage } \\
\text { Difference (ft) }\end{array}$ & $\begin{array}{c}\text { Visual } \\
\text { Advantage } \\
\text { Factor }\end{array}$ & $\begin{array}{c}\text { Number of } \\
\text { Approaches }\end{array}$ \\
\hline \multirow{3}{*}{ DA } & Overcast & 2100 & 616 & 1484 & 3.4 & 30 \\
\cline { 2 - 7 } & Broken & 3460 & 2540 & 920 & 1.4 & 5 \\
\cline { 2 - 7 } & Weighted Average & 2294.0 & 890.7 & 1403.3 & 3.1 & \\
\hline \hline \multirow{3}{*}{$100 \mathrm{ft}$ RA } & Overcast & 1412 & 485 & 927 & 2.9 & 54 \\
\cline { 2 - 7 } & Broken & 1543 & 1460 & 83 & 1.1 & 6 \\
\hline \hline \multirow{3}{*}{ TD } & Weighted Average & 1424.9 & 582.2 & 842.7 & 2.7 & \\
\cline { 2 - 7 } & Overcast & 1267 & 594 & 673 & 2.1 & 47 \\
\cline { 2 - 7 } & Broken & 1380 & 1170 & 210 & 1.2 & 5 \\
\hline \hline
\end{tabular}

Two different types of sky cover were reported during the flight test, overcast and broken. The majority of approaches (89\%) were flown under overcast conditions. Under these two sky covers, the average forward horizontal visible distance provided by the EFVS was greater than that provided by natural vision at the DA, $100 \mathrm{ft}$ RA, and TD approach points (Figure 11). On average, the EFVS provided visual distances 1.2 to 2.8 times greater than natural vision when flown in broken and overcast conditions, respectively. The visual advantage difference ranged from 83 to 1484 feet with weighted averages between 629 and $1403 \mathrm{ft}$. The visual advantage factor ranged from 1.1 to 3.4, with weighted averages between 2.0 and 3.1 (see Table 5). Again, both metrics indicate that an increase in forward horizontal visible range was provided by the EFVS compared to natural vision under two different types of sky cover. 


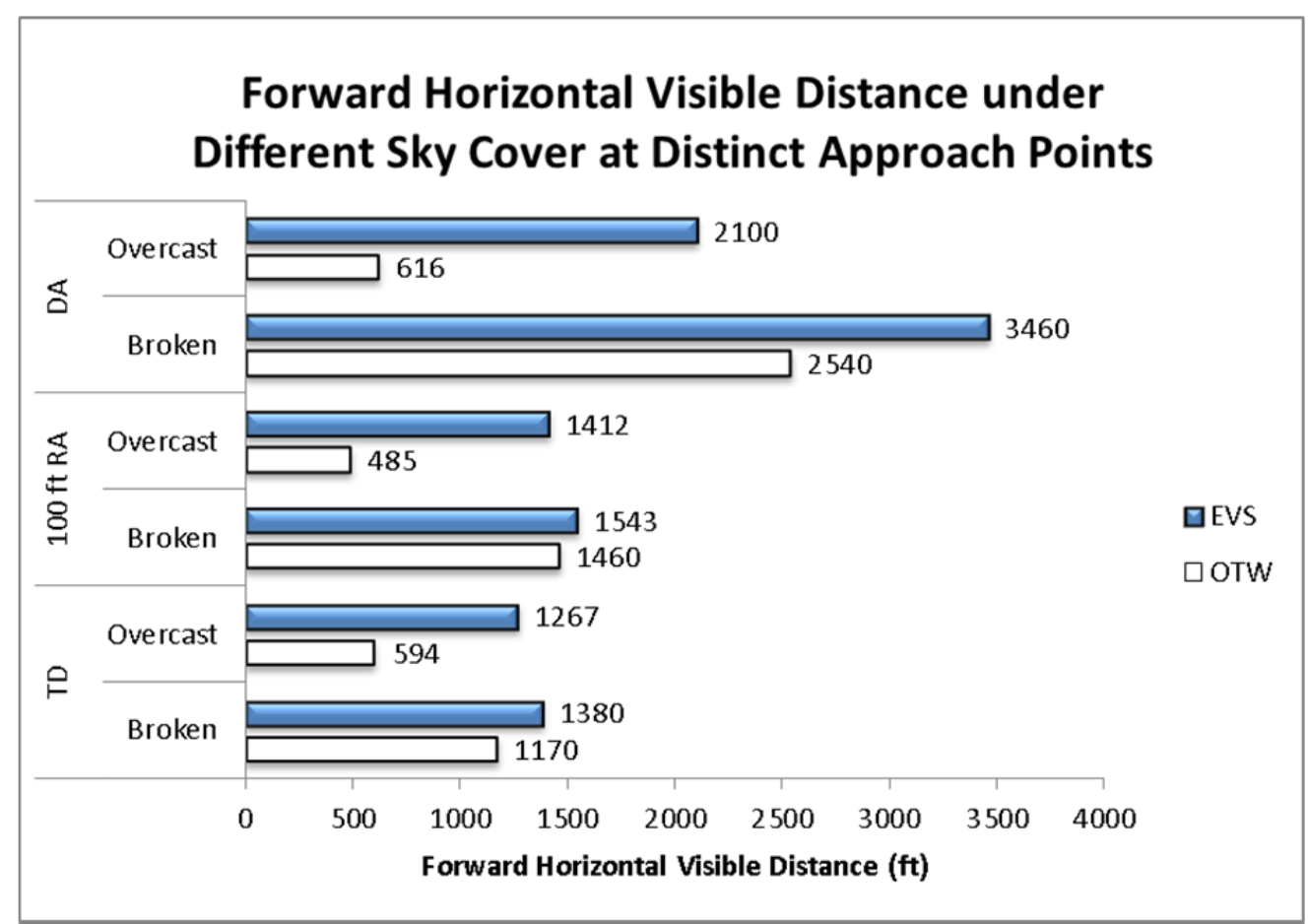

Figure 11. Forward horizontal visible distance under different sky cover at distinct approach points.

\subsection{Visual advantage by ceiling and approach point}

The ceiling during each flight of the flight test was reported as 100 feet, 200 feet, 300 feet, or 500 feet. The forward horizontal visible distance from the cockpit with the EFVS and natural vision was calculated at DA, $100 \mathrm{ft} \mathrm{RA}$, and TD, under these four different ceilings (Table 6 and Figure 12). Under the ceiling levels flown, the EFVS provided a visible range increase at least equivalent to or greater than that provided OTW. The visual advantage difference metric ranged from 600 to $2109 \mathrm{ft}$, with weighted averages ranging from 629 to 1403 . Across the combinations of approach point and ceiling, the visual advantage factor ranged from 1.8 to 5.5, with weighted averages ranging from 2.1 to 2.5 , as seen in Table 6. Under the ceiling levels flown, pilots had more than twice the forward horizontal distance from the cockpit (i.e., a much better visual image of the runway environment) when using the EFVS than when using natural vision.

Of the runs evaluated in this paper, $80 \%$ of the DA approaches, $61 \%$ of the $100 \mathrm{ft}$ RA approaches, and $69 \%$ of the landings were flown under a $100 \mathrm{ft}$ ceiling. For these approaches, the EFVS provided approximately two times more forward visible distance than that provided by natural vision which mirrors the results found with the weighted visual advantage factors at the three approach points. 
Table 6. Visual advantage under different ceilings at distinct points of approach.

\begin{tabular}{|c|c|c|c|c|c|c|}
\hline $\begin{array}{l}\text { Approach } \\
\text { Point }\end{array}$ & Ceiling (ft) & $\begin{array}{c}\text { EFVS } \\
\text { Distance } \\
\text { (ft) }\end{array}$ & $\begin{array}{c}\text { OTW } \\
\text { Distance } \\
\text { (ft) }\end{array}$ & $\begin{array}{c}\text { Visual } \\
\text { Advantage } \\
\text { Difference (ft) }\end{array}$ & $\begin{array}{c}\text { Visual } \\
\text { Advantage } \\
\text { Factor }\end{array}$ & $\begin{array}{l}\text { Number of } \\
\text { Approaches }\end{array}$ \\
\hline \multirow{5}{*}{ DA } & 500 & 2109 & 0 & 2109 & - & 1 \\
\hline & 300 & - & - & - & - & 0 \\
\hline & 200 & 2494 & 779 & 1715 & 3.2 & 6 \\
\hline & 100 & 2258 & 946 & 1311 & 2.4 & 28 \\
\hline & "Weighted Average & 2294.0 & 890.7 & 1403.3 & 2.5 & \\
\hline \multirow{5}{*}{$100 \mathrm{ft}$ RA } & (2500 & $18 \bar{c}$ & 焉 & 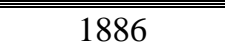 & - & 1 \\
\hline & 300 & 966 & 0 & 966 & - & 1 \\
\hline & 200 & 1536 & 456 & 1080 & 3.4 & 15 \\
\hline & 100 & 1386 & 653 & 733 & 2.1 & 43 \\
\hline & Weighted Average & 1424.9 & 582.2 & 842.7 & 2.4 & \\
\hline \multirow{5}{*}{ TD } & 500 & 11100 & 200 & 900 & 5.5 & 1 \\
\hline & 300 & 1200 & 600 & 600 & 2.0 & 1 \\
\hline & 200 & 1111 & 450 & 661 & 2.5 & 14 \\
\hline & 100 & 1350 & 740 & 610 & 1.8 & 36 \\
\hline & "Weighted Average & 1277.9 & 649.0 & 628.8 & 2.1 & \\
\hline
\end{tabular}

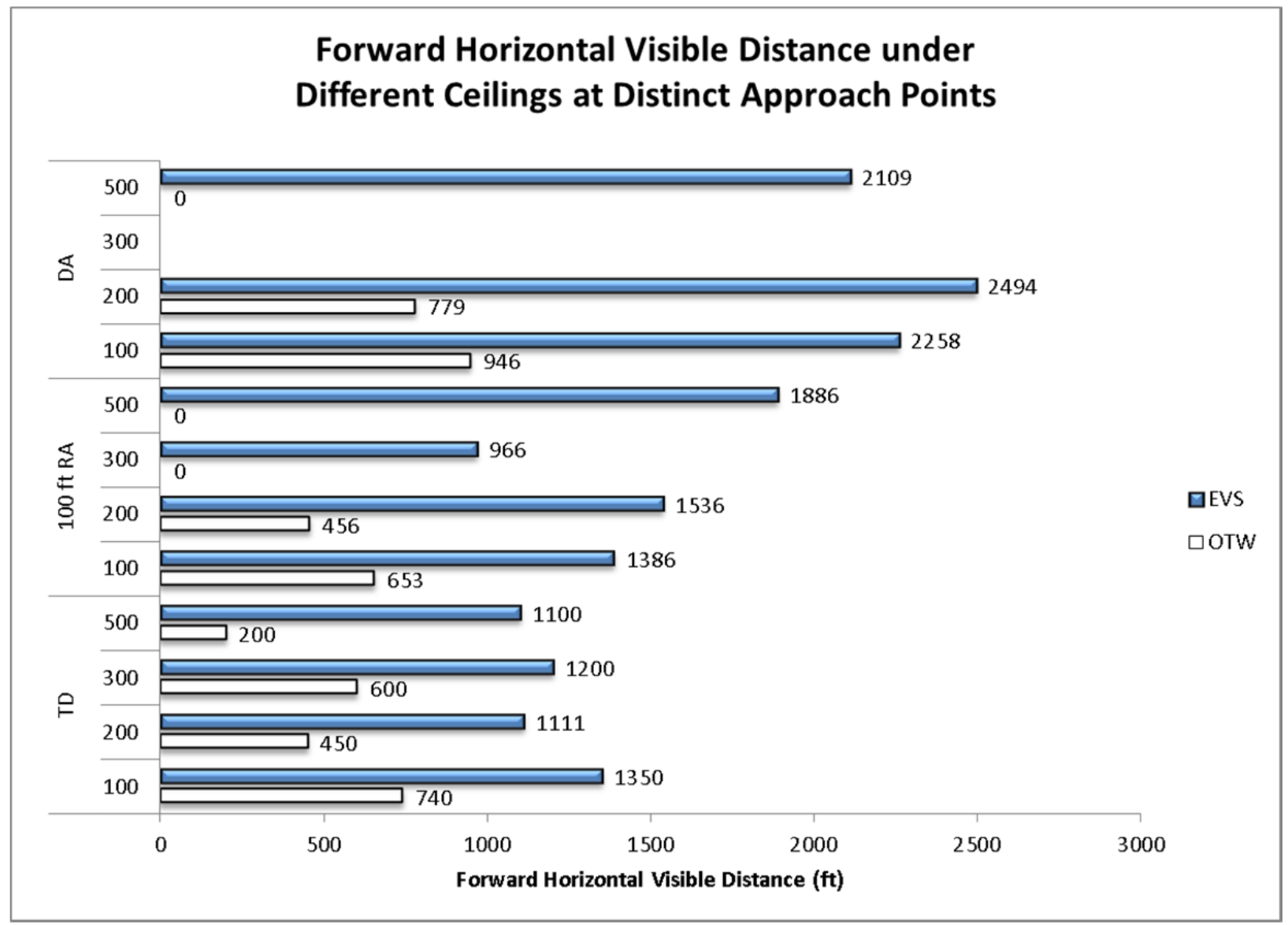

Figure 12. Forward horizontal visible distance under different ceilings at distinct approach points. 


\subsection{Caveats}

The results generally show a visual advantage of EFVS over natural vision. These results correlate well with the operational advantage identified by the evaluation pilots in the flight test. ${ }^{11}$ This advantage was quantified using postflight video analysis. In doing this analysis, several caveats or considerations must be considered in the universal applicability or general validity of the method. Significant differences between this post-flight analysis method and realtime flight operations include the factors:

a) the resolution and dynamic range of the video cameras and recording devices used to capture the data;

b) the monitors to view the recorded data;

c) the imaging differences between the EFVS raw data video used in the analysis and the EFVS video as shown on the HUD for the EP;

d) the imaging differences between the raw data OTW video used in our analysis and the pilot's view through the windows for the EP

e) Field of view, position, and alignment of the respective cameras

By design of the G450 test vehicle, the EFVS cameras and OTW video camera had very similar field-of-view, positioning, and alignment so good comparison was afforded for this factor. Calibration methods would be necessary to verify the other factors; these were not conducted.

The most dramatic differences between the methods, however, is intrinsic: a post-flight, full attention, frame-by-frame examination of video data by an analyst versus a real-time flying operation performed by a pilot flying in very low visibility conditions.

This is not the 'final' word on EFVS visual advantage, and past performance is not necessarily a reliable indicator for future results. In particular, the performance of the EFVS is highly dependent upon the atmospheric conditions, among other factors. The visual advantage does demonstrate, however, the significant improvement that the EFVS II system installed in the G450 provided during this flight test.

\section{SUMMARY}

A team of Honeywell, Gulfstream Aerospace Corporation, and NASA personnel conducted a flight test with the goal of obtaining pilot-in-the-loop test data for flight validation, verification, and demonstration of selected SVS and EFVS operational and system-level performance capabilities in actual very low visibility conditions. Nine test flights (38 flight hours) were conducted over the summer and fall of 2011. The evaluations were flown in Gulfstream's G450 flight test aircraft outfitted with the certified SVS and EFVS technology. Evaluation pilots flew 108 approaches in low visibility weather conditions (as low as $600 \mathrm{ft}$ visibility) into various airports from Louisiana to Maine.

Video from 73 EFVS approaches were reviewed at decision altitude, $100 \mathrm{ft}$ radar altitude, and touchdown approach points to determine if EFVS imagery provided average forward horizontal visible distance increases over that of natural vision - a visual advantage. Pilots flew approaches in low visibility weather conditions (600 to $3600 \mathrm{ft}$ reported visibility with ceilings between 100 and $500 \mathrm{ft}$ ) under different obscurants (mist, fog, drizzle fog, frozen fog) and sky cover (broken, overcast).

Weighted average results indicate the EFVS (FLIR imagery on a HUD) provided increases in average forward horizontal visual distance from the cockpit (visual advantage) of two to three times over that of the out-the-window (OTW) view for the pilot flying. The EFVS allowed pilots to view the runway environment, specifically runway lights, before they would be able to OTW with natural vision. The visual advantage afforded by the EFVS over natural vision provides operational data that supports proposed rulemaking where EFVS could be used continuously throughout the approach, landing, and roll-out in visibilities as low as $1000 \mathrm{ft}$ RVR in lieu of natural vision.

The performance of the EFVS sensor was generally outstanding, providing the required visual approach and landing references clearly beyond that of the natural vision. Actual weather flying continually demonstrated and emphasized how non-homogeneous weather conditions can affect EFVS performance. FLIR-based sensor technology used in conjunction with the HUD enabled successful approaches to landings in reported visibility as low as 600 RVR. However, EV sensor technologies (other than FLIR) for improved all-weather operations when the reported visibility is 
less than $1000 \mathrm{ft}$ RVR are needed. The visual advantage afforded by the EFVS over natural vision allows a pilot to see much more of the approach runway environment (i.e., required visual approach and landing references), increase pilots' situational awareness, and provide more visual cues (e.g., visual momentum, optical flow, etc.) which could aid stabilized approach maintenance for a safer landing.

\section{ACKNOWLEDGMENTS}

This work was jointly sponsored by NASA's Aviation Safety Program (AvSP), Vehicle Systems Safety Technologies project (Mr. Paul Krasa, Project Manager). The flight test data in this analysis was produced under an IA between NASA and the FAA Human Factors R\&D Project for NextGen, led by Dr. Tom McCloy, Mr. Dan Herschler, and Mr. Stephen Plishka. Programmatic support and technical advice from these groups was gratefully appreciated. The team is also grateful for the technical support of Mrs. Terry King, the contribution of Glenn Connor as our weather guru, and the hard work and diligence of Trish Ververs of Honeywell and Chip King (Gulfstream) in completing a tremendously successful

flight test program.

\section{REFERENCES}

[1] Joint Planning and Development Office. (2008). Next generation air transportation system integrated plan: A functional outline. Washington, DC: Author.

[2] Federal Aviation Administration. (n.d.). Instrument flight procedures (IFP) inventory summary. Retrieved February 28, 2011, from http://www.faa.gov/air_traffic/flight_info/aeronav/ifpinventorysummary.

[3] Federal Aviation Administration. (2010). Airworthiness approval of enhanced vision system, synthetic vision system, combined vision system, and enhanced flight vision system equipment (FAA Advisory Circular 20-167). Washington, DC: Author..

[4] Federal Aviation Administration. (2010). Enhanced flight vision systems (FAA Advisory Circular 90-106). Washington, DC: Author.

[5] Connor, G. (2011, April). On the road to zero-zero. Professional Pilot, 22-27.

[6] Federal Aviation Administration. (2012). Enhanced flight vision systems (FAA RIN 2120-AJ94). Retrieved May 1, 2013, from http://www.reginfo.gov/public/do/eAgendaViewRule?pubId=201210\&RIN=2120-AJ94.

[7] RTCA. (2010). Minimum aviation system performance standards (MASPS) for enhanced vision systems, synthetic vision systems, combined vision systems, and enhanced flight vision systems (Tech. Rep. DO-315A). Washington, DC: RTCA.

[8] Bailey, R. E., Kramer, L. J., and Williams, S. P. (2010). Enhanced vision for all-weather operations under NextGen. Proceedings of SPIE Enhanced and Synthetic Vision Conference 2010, 7689, pp. 768903-1-768903-18.

[9] Federal Aviation Administration. (2013). Revisions to operational requirements for the use of enhanced flight vision systems (EFVS) and to pilot compartment view requirements for vision systems (FAA-2013-0485, Notice No.1209). Washington DC: DOT/FAA. Retrieved June 11, 2013. from http://www.gpo.gov/fdsys/pkg/FR-2013-0611/pdf/2013-13454.pdf\#page=1.

[10] Kramer, L. J., Bailey, R. E., Ellis, K. K., Williams, S. P., Arthur, J. J., III, Prinzel, L. J., III, \& Shelton, K. J. (2013). Enhanced flight vision systems and synthetic vision systems for NextGen approach and landing operations (NASA Technical Publication 218054). Washington, DC: NASA:

[11] Shelton, K. J., Kramer, L. J., Ellis, K. K., \& Rehfeld, S. A. (2012). Synthetic and enhanced vision systems for NextGen (SEVS) simulation and flight test performance evaluation. Proceedings of the 31st Digital Avionics Systems Conference, 2D5-1-2D5-12. 